\title{
Partial Mullerian Agenesis with Renal and Skeletal Anomalies: An Observational Study of MURCS Association
}

\author{
Shirin Jahan ${ }^{1 *}$, Sumaiya Akter ${ }^{2}$
}

${ }^{1}$ MBBS, FCPS, MS (Obs and Gynae) Junior Consultant Department of Reproductive Endocrinology and Infertility, Banganbandhu Sheikh Mujib Medical University (BSMMU) Dhaka, Bangladesh

${ }^{2}$ MBBS, FCPS (Obs and Gynae) Obstetrician and Gynaecologist Department of Reproductive Endocrinology and Infertility Banganbandhu Sheikh Mujib Medical University (BSMMU) Dhaka, Bangladesh

\section{DOI: $10.36348 /$ sijog.2022.v05i01.001}

| Received: 07.12.2021 | Accepted: 12.01.2022 | Published: 15.01.2022

*Corresponding author: Shirin Jahan

MBBS, FCPS, MS (Obs and Gynae) Junior Consultant Department of Reproductive Endocrinology and Infertility, Banganbandhu Sheikh Mujib Medical University (BSMMU) Dhaka, Bangladesh

Email: "shirin.dr@gmail.com

\section{Abstract}

Background: Müllerian agenesis is a disorder of genital development characterized by absence of the vagina, an absent or hypoplastic uterus, and normal or hypoplastic fallopian tubes. Typically, the ovaries are entirely normal, although one or both also may be undescended, hypoplastic, or associated with an inguinal hernia. Affected patients often also have urologic anomalies (15-40) \% (unilateral renal agenesis, ectopic or horseshoe kidney, and duplication of the collecting systems) and skeletal malformations (5-10) \%, (e.g., hemiverterbrae and scoliosis, or the Klippel-Feil syndrome). The cause is unknown, although some cases are associated with chromosomal translocations or occur in familial aggregates, suggesting a genetic basis. Logically, müllerian agenesis might be attributed to an activating mutation in the gene encoding AMH or its receptor, causing excess AMH activity, but none have been identified. Aim: The aim of this study was to analyze and present rare cases of partial mullerian agenesis combined with renal and/or skeletal malformations, their causes, clinical features, diagnosis and treatment along with review of literatures. Methods: A retrospective observational study was conducted in the department of Bangabandhu Sheikh Mujib Medical University. All four cases presented with similar type of presentation and were diagnosed as partial Mullerian aplasia (cervico-vaginal agenesis) with other associated anomalies (renal, skeletal or cardiac anomalies) ie: MURCS association. Results: We analysed four cases of mullerian agenesis with renal and/or skeletal abnormalities presented with primary amenorrhoea with cyclical lower abdominal pain. Subsequently these patients were ascertained to have cervicovaginal agenesis with renal and skeletal abnormalities by physical examination and relevant investigations. Two (50\%) patients had renal anomalies in the form of renal agenesis and one small malrotated kidney while $100 \%$ patients had skeletal abnormalities. One (25\%) patient had congenital cardiac anomaly, one (25\%) patient had history of cleft lip and cleft palate and one (25\%) patient had history of imperforated anus at birth. Evaluation included clinical examination, whole abdominal ultrasound, skeletal survey and karyotyping along with some supportive investigations. Conclusion: The management is varied but multidisciplinary approach, psychological and social supports are the key points of managing such cases.

Keywords: Mullerian agenesis, renal anomaly, skeletal malformation.

Copyright (C) 2022 The Author(s): This is an open-access article distributed under the terms of the Creative Commons Attribution 4.0 International License (CC BY-NC 4.0) which permits unrestricted use, distribution, and reproduction in any medium for non-commercial use provided the original author and source are credited.

\section{INTRODUCTION}

MRKH syndrome patients presents with primary amenorrhoea and or failed attempt of coitus [1]. This syndrome is of two types. Type I occurs as a purely genital malformations characterized by congenital aplasia of the uterus and the upper part (2/3) of the vagina in women showing normal development of secondary sexual characteristics and a normal 46, XX karyotype. Type

II MRKH syndrome occurs as incomplete aplasia and/or associated with other malformations generally referred to as MURCS association: 
Shirin Jahan \& Sumaiya Akter; Sch Int J Obstet Gynec, Jan. 2022; 5(1): 1-6

- Renal (unilateral agenesis, ectopia of kidneys or horseshoe kidney)

- $\quad$ Skeletal and, in particular, vertebral (Klippel-Feil anomaly; fused vertebrae, mainly cervical; scoliosis)

- Hearing defects

- More rarely, cardiac and digital anomalies (syndactyly, polydactyly) [2]

MRKH patients have their pubarche and thelarche in proper time and have a normal female karyotype (46, XX) [3]. The syndrome was first described by Mayer [4] in 1829, and Rokitansky [5] published a case report on these malformations later. In 1910, Küster wrote the first review on the syndrome [6]. Hauser and Schreiner were the first to name it Mayer-Küster-Rokitansky syndrome in 1961[7]. Finally, Hauser's name is added resulted in today's term, Mayer-Rokitansky-Küster-Hauser syndrome.

The incidence of the MRKH syndrome is one in 4,500 female newborns [1]. True incidence of cervicovaginal agenesis is still unknown.[8] The prevalence of vaginal agenesis is 1 in 4000-5000 live female births,[9] whereas that of cervical agenesis is 1 in 80,000-10,0000 live births [10]. These patients are phenotypically females with normal female genotypes and normal endocrine status. A failure of fusion of Müllerian duct derivatives during gestational weeks 412 results in malformation of the vagina and uterus [3]. However, the precise pathogenetic mechanism is still unknown. Abnormal fusion, formation, or reabsorption of the Müllerian ducts during fetal life result in congenital malformations of the female urogenital tract, which may be partial or complete [11].

Type 1 MRKH is less frequent than MURCS association. Type $2 \mathrm{MRKH}$ is often associated with anomalies of the renal $(40 \%-60 \%)$ system, skeletal (20\%) systems, and cervico-thoracic somite dysplasia (MURCS) [12].

\section{METHODS}

A retrospective observational study was conducted in the department of Bangabandhu Sheikh Mujib Medical University. All cases presented with similar type of presentation and were diagnosed as partial Mullerian aplasia (cervico-vaginal agenesis) with other associated anomalies (renal, skeletal or cardiac anomalies) ie: MURCS association. Patient's file and hospital's medical records were reviewed for analysis of these similar cases and evaluation of surgical feasibility and anatomical and functional outcome. Patient's informations regarding preoperative history, clinical examination, abdomino-pelvic's ultrasound, magnetic resonance imaging (MRI) of abdomino-pelvic organs, hormonal profile and karyotyping were collected. Diagnosis and treatment options were discussed with the patients and their parents. Surgical procedure along with all possible complications and postoperative care (course) were explained in detail as well.

\section{Case 1}

Miss X 20 year's old unmarried girl of low socioeconomic condition from Khagrachhari was admitted to department of Reproductive Endocrinology and Infertility with the complaints of primary amenorrhoea and lower abdominal pain for 6 years. She was apparently healthy since her birth and grown up normally like other girls of similar age. Her secondery sexual characteristics developed at 11 years of age but her menstruation has not yet established. She complained of occasional lower abdominal pain which was intermittent, colicky in nature and non- radiating. Pain was not associated with fever, dysuria, and constipation or vomiting. Her bowel and bladder habits were normal. She gave no history of acute retention of urine, trauma or contact with tuberculosis. There was no family history of primary amenorrhoea or tuberculosis. On physical examination, she had kyphosis, her BMI was $16 \mathrm{~kg} / \mathrm{m}^{2}$ and she was non anaemic. Secondary sexual characteristics were normal (breast- Tanner stage 4, and axillary and pubic hair distributions were normal. A tender hypogastric mass of about 14 weeks size was palpable on abdominal examination. Lower limit of the lump could not be reached. Vagina was blind and there was no palpable bulging in the anterior rectal wall. She was diagnosed as a case of Primary amenorrhoea due to cervicovaginal agenesis with haematometra with small and malrotated right kidney with congenital heart disease.

Table-1: Investigations findings of Case 1

\begin{tabular}{|l|l|}
\hline Name of Investigations & Value \\
\hline SerumTSH & $2.39 \mu \mathrm{IU} / \mathrm{ml}$ \\
\hline Serum FSH & $4.22 \mathrm{mIU} / \mathrm{ml}$ \\
\hline Serum LH & $8.64 \mathrm{mIU} / \mathrm{ml}$ \\
\hline Prolactin & $20.57 \mathrm{ng} / \mathrm{ml}$ \\
\hline USG of Whole Abdomen & $\begin{array}{l}\text { Ectopic small right kidney (just above the umbilicus } 5 \times 2.3 \mathrm{~cm}) \\
\text { Multiseptated cyst in right ovary }(6.3 \times 3.4) \text { Thick and irregular endometrium }\end{array}$ \\
\hline CT Urogram & $\begin{array}{l}\text { Smaller malrotated right kidney with normal contrast excretion. Faint longitudinal septum in the upper } \\
\text { part of left ureter resulting focal dilatation }\end{array}$ \\
\hline Echocardiography & $\begin{array}{l}\text { Multiple congenital heart diseases including ASD, perimembranous VSD, right to left shunt, moderate } \\
\text { PR, TR with severe pulmonary hypertension, non-completed cardiomyopathy involving LV and RV. }\end{array}$ \\
\hline Karyotyping & $46 X X$ \\
\hline
\end{tabular}


Counselling was done with patient's relative (mother and brother) about the diagnosis and next (operative) management options and their outcome. Management include: (1) Total abdominal Hysterectomy, (2) Neovaginoplasty with excision of atretic cervix and uterovaginal anastomosis with its further complications, (3) Continuous OCP until further decision. After counselling, patient gave consent for total abdominal hysterectomy. Under epidural analgesia, abdomen was opened by Pfannenstiel incision there was reddish fluid in the peritoneal cavity. Hematosalphinx was found in the left side. Upper two third of the uterus was well formed but lower one third was underdeveloped. Cervix was absent and was replaced by a cord like structure. Vagina was absent. There was adhesion between left side of fallopian tube, left ovary and bowel. After successive clamping, cutting and ligating, total abdominal hysterectomy with right sided cystectomy was done. Peritoneal toileting was done with normal saline. A drain tube was kept in situ. Abdomen was closed in layers.

\section{Case 2}

Miss. Y, 18 years old SSC student, was admitted in the department of Reproductive Endocrinology and Infertility, BSMMU with the complaints of non-establishment of menstruation till date, cyclic lower abdominal pain for two years which becomes continuous for the last two months. She was born with multiple congenital anomalies (cleft lip and cleft palate). Her secondary sexual characteristics developed at 12 years of age but her menstruation has not yet established. She complained of cyclical lower abdominal pain for two years and continuous lower abdominal pain for the last two months. Pain was not associated with fever, dysuria or constipation. She also gave no history of acute retention of urine, trauma or contact with Tuberculosis nor does she have any family history of primary amenorrhoea or tuberculosis. Her mother was diagnosed as having gestational Diabetes mellitus at four months of gestation. She had undergone corrective surgery for cleft lip and cleft palate 13 years back.

On examination, she was short statured with kyphoscoliosis and her upper part of the body was underdeveloped. She has flexion deformities of knee. Her weight was $31 \mathrm{~kg}$, height was $125 \mathrm{~cm}$ and BMI was $19.84 \mathrm{~kg} / \mathrm{m}^{2}$. Her secondary sexual characteristics were well developed (Breast: Tanner stage 5 with normal axillary and pubic hair distribution). A hypogastric mass of about 20 weeks size was palpable which was tender and cystic in consistency. Labia majora and minora were underdeveloped and vagina was capacious but blind. Cervix and uterus were not felt per vagina. Per rectal examination revealed a cystic bulging in the anterior rectal wall four $\mathrm{cm}$ above the anus.

Finally she was diagnosed as a case of primary amenorrhoea due to cervico vaginal agenesis with hematometra with hematosalpinx with skeletal abnormality with history of multiple congenital abnormalities. After counselling she was also managed by total abdominal hysterectomy.

Table-2: Investigations findings of Case 2

\begin{tabular}{|l|l|}
\hline Name of Investigations & Value \\
\hline TSH & $1.04 \mu \mathrm{IU} / \mathrm{ml}$ \\
\hline FSH & $5.37 \mathrm{mIU} / \mathrm{ml}$ \\
\hline LH & $9.42 \mathrm{mIU} / \mathrm{ml}$ \\
\hline Prolactin & $16.5 \mathrm{ng} / \mathrm{ml}$ \\
\hline USG of lower abdomen & Aplastic uterus with bilateral rudimentary horn with cavity \\
\hline Echocardiography & Good left ventricular systolic function (EF-72\%) \\
\hline Skeletal survey & $\begin{array}{l}\text { Scoliosis of bony thorax and dorsolumber spine, block vertebra is noted at D6 and D7, } \\
\text { dislocation of left hip joint, left acetabulum is markedly short, tilting of pelvis towards left, } \\
\text { depressed nasal bone, fibula was absent on right and left proximal fibula is absent. }\end{array}$ \\
\hline MRI of abdomen & $\begin{array}{l}\text { Congenital malformation of uterus with two septate upper uterine cavity and left ovarian } \\
\text { benign cyst with hydrosalphinx, lower limit of uterus, cervix and vagina could not be identified }\end{array}$ \\
\hline Karyotyping & 46XX \\
\hline
\end{tabular}

\section{Case 3}

Miss S, 16 years old girl of class ten from Gazipur was admitted in the Department of Reproductive Endocrinology and Infertility, BSMMU with primary amenorrhoea and cyclical lower abdominal pain. She was born with multiple congenital anomalies which include imperforate anus and skeletal abnormality like small right foot and polydactyly of left foot. At $6^{\text {th }}$ day of her life she had undergone surgery for imperforate anus. After that she was grown up normally like other girls. In spite of normally developing secondary sexual characteristics, menstruation has not yet been established. She was a known case of hypothyroid. On examination, her BMI was $21 \mathrm{~kg} / \mathrm{m}^{2}$, breast; Tanner stage -5 , axillary and pubic hair were present with normal female pattern. Vagina was blind and right foot was smaller than left one and there is extra digit in left foot. Per rectal examination could not be done due to narrowing of anal opening. 
Shirin Jahan \& Sumaiya Akter; Sch Int J Obstet Gynec, Jan. 2022; 5(1): 1-6

Table-3: Investigations findings of Case 3

\begin{tabular}{|l|l|}
\hline Name of Investigations & Value \\
\hline Serum TSH & $2.52 \mu \mathrm{IU} / \mathrm{ml}$ \\
\hline Serum FT4 & $1.21 \mathrm{ng} / \mathrm{dl}$ \\
\hline Serum FSH & $8.6 \mathrm{mIU} / \mathrm{ml}$ \\
\hline Serum Estradiol & $43.3 \mathrm{pg} / \mathrm{ml}$ \\
\hline Serum Testosterone & $1.32 \mathrm{mmol} / \mathrm{L}$ \\
\hline Echocardiography & Normal \\
\hline USG of Whole Abdomen & $\begin{array}{l}\text { Non-visualized right kidney, compensatory hypertrophy of left kidney with } \\
\text { mild hydronephrosis and uterus is hypoplastic }(5.5 \mathrm{X} 2.7 \mathrm{X} 2.8) \mathrm{cm}\end{array}$ \\
\hline Karyotyping & $46 \mathrm{XX}$ \\
\hline
\end{tabular}

Finally she was diagnosed as a case of primary amenorrhoea due to cervicovaginal agenesis with renal agenesis with polydactyly. After counselling her guardian, total abdominal hysterectomy was done. Neovaginoplasty will be done at later date when she will be ready for intercourse.

Operation note: Abdomen was opened through Pfannenstiel incision. Intestine was found adherent with the anterior abdominal wall. Then adhesiolysis was done. There was unicornuate uterus of about $(4 \mathrm{X} 3 \mathrm{~cm})$ size with no cervix. Left ovary and tube was found and after exploration right ovary and distal fimbriated end of the right tube was found. In between the right ovary, tube and left horn of the uterus, no uterine tissue was present. Cervix was not felt. Then after proper clamping, cutting and ligating, hysterectomy was done. A drain tube was kept in situ. After counting mops and instruments and ensuring proper haemostasis, abdomen was closed in layers.

\section{Case 4}

Miss T, 16 year student of class ten was admitted in BSMMU with primary amenorrhoea and cyclical lower abdominal pain with previous history of vaginoplasty three times. Her secondary sexual characteristics developed at her 12 years of age but these events were not followed by menstruation. She felt cyclical lower abdominal pain and consulted with local doctor and had three times vaginoplasty operation but her symptoms persisted and restenosis occured. She had undergone laparoscopic cystectomy before her third vaginoplasty operation. She was prescribed oral contraceptive pill continuously for suppression of menstruation and prevention of development of further complications like haematometra, haematosalpinx and pelvic endometriosis. On examination, patient was restless, anxious and agitated. Her secondary sexual characteristics were well developed (Tanner stage V). There was a lump felt just above the pubic symphysis which was mildly tender. Vagina was about $2 \mathrm{~cm}$ with blind end. Cord like structure was felt per rectally. Polydactyly were found in all four limbs. Ultrasonogram shows, absence of cervix and vagina, haematometra with left sided adnexal cyst with right sided pelvi-ureteral junction obstruction. Hormonal profile was normal and karyotyping was $46 \mathrm{XX}$. She too had total abdominal hysterectomy with left sided saphingectomy due to haematosalpinx with distorted anatomy with preservation of both ovaries.

\section{RESULTS}

All patients were diagnosed as cervicovaginal agenesis with renal, skeletal and cardiac anomalies or more precisely they can be termed as Type II MRKH (partial mullerian aplasia with other associated anomalies). Age of the patients at the time of diagnosis varied between 16-20 years. All patients were unmarried at the time of presentation. All of them $(100 \%)$ presented with primary amenorrhoea with cyclical lower abdominal pain. All of them had normal female appearances with normal secondary sexual characteristics and external genitalia were of female phenotype but vagina was blind felt like a dimple or having only $0-2 \mathrm{~cm}$ varied length. All four patients presented with lower abdominal lump. $100 \%$ patients had normal hormonal profile. USG revealed absence of cervix and vagina in all cases and haematometra in all four cases. Three out of four $(75 \%)$ patients had adnexal cyst or masses. All patients had normal karyotype. $50 \%$ patients had renal abnormality, $100 \%$ patients had skeletal abnormality and $25 \%$ patients had cardiac abnormality. One out of four patients had history of cleft lip and cleft palate which was corrected during childhood and one patient had history of imperforated anus that too was corrected just after birth. All patients underwent hysterectomy after counselling about the possible treatment options with success rate and complications.

Table-4: Percentages of different anomalies in this study

\begin{tabular}{|l|l|l|}
\hline Associated Anomalies & Total number of patients $(\mathbf{n}=4)$ & Percentages \\
\hline Renal anomalies & 2 & $50 \%$ \\
\hline Skeletal anomalies & 4 & $100 \%$ \\
\hline Cardiac anomalies & 1 & $25 \%$ \\
\hline History of cleft lip and cleft palate & 1 & $25 \%$ \\
\hline History of imperforated anus & 1 & $25 \%$ \\
\hline
\end{tabular}


Shirin Jahan \& Sumaiya Akter; Sch Int J Obstet Gynec, Jan. 2022; 5(1): 1-6

\section{DISCUSSION}

Diagnosis of cervico-vaginal agenesis is usually done by typical history of primary amenorrhea with cyclic lower abdominal pain. Clinical examination reveals normal secondary sexual characteristics with occasional lower abdominal lump. Transabdominal or trans-perineal ultrasonography may specify the level of obstruction and agenesis but are not very reliable for the diagnosis. MRI can reliably diagnose the uterovaginal malformation and other associated malformations with most accuracy [13]. Intravenous pyelography, echocardiography and karyotyping may help rule out other associated malformations.

The recommended treatment of cervicovaginal agenesis includes hysterectomy because of high failure rate of canalization procedures and risk of serious ascending infection. But recent advances in minimal surgery have replaced this approach by conservative approach [14]. Basic surgical principle is to create neovagina. Neovagina creation is followed by the resection of atretic or cord-like cervical tissue if present and uterovaginal anastomosis [15]. This conservative surgery should be done in adolescence period before developing any cpmplications like haematometra, haematosalpinx, endometrioma or severe pelvic endometriosis to avoid these longstanding complications which can hamper fertility potential badly [15]. However, even after such surgery, patients on long term are at risk of stenosis, requiring revision surgery. Repeated episodes of hematometra, endometriosis, and recurrent stenosis or obstruction might require hysterectomy as a last option [16].

Patient's medical history, preferences, motivation, lifestyle and underlying condition, along with the surgeons' efficiency play an important role in choosing correct approach. However timing for creation of a neovagina is elective and is best planned when the patient is emotionally mature, highly motivated and express desire for correction. Different nonsurgical and surgical techniques are available to treat this anomaly. However, at present there is no consensus in literature regarding the best procedure for surgical correction to afford the best functional outcome and sexual satisfaction [17].

The genetics of MRKH syndrome is complex and difficult to understand completely. [18]. Some researchers showed that several cases of MRKH have been associated with loss-of-function mutations in the WNT4 gene [18-20]. Cumulative evidence suggests that Müllerian Agenesis/MRKH Syndrome maybe genetically related and found to be inherited as autosomal dominant trait with incomplete penetrance (individuals who inherit the gene for a dominant disorder won't be affected by it) and variable expressivity (the inherited dominant gene for the disorder can present variable signs and symptoms in the affected individual) [21].
In this study, all four cases were diagnosed as cases of cervico-vaginal agenesis associated with other renal, cardiac and skeletal abnormalities. As the excretory (kidneys) and urinary systems develop concomitantly with the mullerian duct systems [22], Müllerian Agenesis, is usually accompanied by anomalies in these systems such as renal agenesis, horse shoe kidney or fused kidneys [22-24]. The axial skeletal defects such as scoliosis (abnormal lateral curvature of the spine), which accompanies the MRKH syndrome frequently occurs due to interruption in the developing mesoderm and its adjacent somites in the embryo. Vertebrae bones of the neck (cervical vertebrae) and the upper part of the back (thoracic vertebrae) may mature inadequately (dysplasia) causing some of the vertebrae within the neck to be missing and/or fused, causing shortness of the neck, limited range of motion, and an aberrantly low hairline (Klippel-Feil syndrome) [2527].

Multidisciplinary approach was undertaken and urologic, cardiologic and orthopaedic consultations were done for managing these patients. All these patients were of low socio-ecnomic background and suffered a lot before coming to this tertiary level hospital. Three-fourth patients developed endometrioma, severe pelvic endometriosis and dense adhesion that hampered their fertility potential and made their life miserable due to pain. Hence after counselling, considering their sufferings, fertility potential and economic condition, all of them chose total abdominal hysterectomy as a better option for them. They were instructed to come for vaginoplasty at a later date when they would be ready to get married or intend to start sexual intercourse. All of them were in better health status after their surgery on follow up.

The closest differential diagnoses of MURCS association are Goldenhar syndrome and VACTERL association. Goldenhar syndrome differs from MURCS association in that urological abnormalities are rare in Goldenhar syndrome that is usually accompanied by the abnormal congenital development of the nose, lip, soft palate, mandible and ear. On the other hand, VACTERL anomaly is characterized by anal atresia, tracheoesophageal fistula, and cardiac defects in addition to vertebral defects, limb abnormalities, and renal anomalies common to Type II MRKH syndrome. Genital malformation is rarely associated with it and vertebral anomalies are more common in the caudal region [11].

\section{CONCLUSION}

The phenotypic manifestations of Type II MRKH syndrome overlap with various other syndromes or associations. Hence, all women with primary amenorrhea with cyclic lower abdominal pain should undergo a complete investigation of both the genital tract and the endocrine system to formulate a proper plan of management that would be best for these 
Shirin Jahan \& Sumaiya Akter; Sch Int J Obstet Gynec, Jan. 2022; 5(1): 1-6

patients according to her physical condition, preference, lifestyle, psychological status and social values. Multidisciplinary approach involving urologist, cardiologist, orthopaedic surgeon, plastic surgeon, psychiatrist, geneticist with sympathetic approach are essential for managing these cases.

\section{REFERENCES}

1. Morcel, K., Guerrier, D., Watrin, T., Pellerin, I., \& Leveque, J. (2008). The Mayer-Rokitansky-KüsterHauser (MRKH) syndrome: clinical description and genetics. Journal de gynecologie, obstetrique et biologie de la reproduction, 37(6), 539-546.

2. Morcel, K., Camborieux, L., \& Guerrier, D. (2007). Mayer-Rokitansky-Küster-Hauser (MRKH) syndrome. Orphanet journal of rare diseases, 2(1), 19.

3. Oppelt, P., Renner, S. P., Kellermann, A., Brucker, S., Hauser, G. A., Ludwig, K. S., \& Beckmann, M. W. (2006). Clinical aspects of Mayer-RokitanskyKuester-Hauser syndrome: recommendations for clinical diagnosis and staging. Human reproduction, 21(3), 792-797.

4. Mayer, C. A. J. (1829). Über Verdoppelungen des uterus und ihre arten, nebst Bemerkungen über Hasenscharte und Wolfsrachen. J Chir Auger, 13, 525-564.

5. Rokitansky, K. (1838). Uber die sogenannten Verdoppelungen des Uterus. Med JB Ost Staates, 26, $39-42$.

6. Kuster, H. (1910). Uterus bipartitus solidus rudimentarius cum vagina solida. Z Geb Gun, 67, 692-718.

7. Hauser, G. A., \& Schreiner, W. E. (1961). MayerRokitansky-Kuester syndrome. Rudimentary solid bipartite uterus with solid vagina. Schweizerische medizinische Wochenschrift, 91, 381-384.

8. Abali, R., Kuvat, S. V., Bozkurt, S., Kayhan, A., Yuksel, M. A., \& Caliskan, H. (2013). Report of surgical correction of a cervicovaginal agenesis case: cervicovaginal reconstruction with pudendal thigh flaps. Archives of medical science: AMS, 9(1), 184.

9. Saxena, A. K., \& Herman, M. I. (2009). Vaginal Atresia. Webpage. Cited June 02, 2009. http://emedicine.medscape.com/article/954110 .

10. Creighton, S. M., Davies, M. C., \& Cutner, A. (2006). Laparoscopic management of cervical agenesis. Fertility and sterility, 85(5), 1510-e13.

11. Ravikanth, R., \& Majumdar, P. (2019). Complete Müllerian agenesis, renal agenesis, and renal ectopia: MURCS association-A rare cause of primary amenorrhea. Apollo Medicine, 16(4), 250.

12. Guerrier, D., Mouchel, T., Pasquier, L., \& Pellerin, I. (2006). The Mayer-Rokitansky-Küster-Hauser syndrome (congenital absence of uterus and vagina)phenotypic manifestations and genetic approaches. Journal of negative results in biomedicine, 5(1), 1-8.

13. Vallerie, A. M., \& Breech, L. L. (2010). Update in Müllerian anomalies: diagnosis, management, and outcomes. Current Opinion in Obstetrics and Gynecology, 22(5), 381-387.

14. Deffarges, J. V., Haddad, B., Musset, R., \& Paniel, B. J. (2001). Utero-vaginal anastomosis in women with uterine cervix atresia: long-term follow-up and reproductive performance. A study of 18 cases. Human reproduction, 16(8), 1722-1725.

15. Acién, P., Acién, M. I., Quereda, F., \& Santoyo, T. (2008). Cervicovaginal agenesis: spontaneous gestation at term after previous reimplantation of the uterine corpus in a neovagina: case report. Human reproduction, 23(3), 548-553.

16. McIndoe, A. (1950). The Treatment of Congenital Abscence and Obliterative Conditions of the Vagina. Plastic and Reconstructive Surgery, 6(1), 89.

17. Laufer, M. R. (2002). Congenital absence of the vagina: in search of the perfect solution. When, and by what technique, should a vagina be created?. Current Opinion in Obstetrics and Gynecology, 14(5), 441-444.

18. Fontana, L., Gentilin, B., Fedele, L., Gervasini, C., \& Miozzo, M. (2017). Genetics of Mayer-RokitanskyKüster-Hauser (MRKH) syndrome. Clinical genetics, 91(2), 233-246.

19. Philibert, P., Biason-Lauber, A., Rouzier, R., Pienkowski, C., Paris, F., Konrad, D., ... \& Sultan, C. (2008). Identification and functional analysis of a new WNT4 gene mutation among 28 adolescent girls with primary amenorrhea and mullerian duct abnormalities: a French collaborative study. The Journal of Clinical Endocrinology \& Metabolism, 93(3), 895-900.

20. Williams, L. S., Eksi, D. D., Shen, Y., Lossie, A. C., Chorich, L. P., Sullivan, M. E., ... \& Layman, L. C. (2017). Genetic analysis of Mayer-RokitanskyKuster-Hauser syndrome in a large cohort of families. Fertility and sterility, 108(1), 145-151.

21. Elumalai, G., \& Egbunine, A. A. C. O. (2017). "Müllerian agenesis" embryologic and clinical significance.

22. Elumalai, G., \& Dharmalingam, A. (2016). Left superior vena cava" embryological basis and its clinical significance. Elixir Embryology, 100, 4342943432.

23. Elumalai, G., \& Anbazhagan, L. (2016). Laryngomalacia" embryological basis and its clinical significance. Elixir Embryology, 100, 43420-43424.

24. Gupta, N. P., \& Ansari, M. S. (2002). MayerRokitansky-Kuster-Hauser (MRKH) syndrome-a review. Indian journal of urology, 18(2), 111.

25. Elumalai, G., \& Chodisetty, S. (2016). Teratological Effects of High Dose Progesterone on Neural Tube Development in Chick Embryos. Elixir Gynaecology, 97, 42085-42089.

26. Ganesh, E., \& Sushma, C. (2016). The deer horn aortic arches" embryological basis and surgical implications. Anatomy Journal of Africa, 5(2), 746-759.

27. ACOG Committee on Adolescent Health Care. (2018). Mullerian agenesis: diagnosis, management, and treatment. ACOG Committee opinion no. 728. Obstet Gynecol, 131, 35-42. 